\title{
Aprendizagem escolar e ação pedagógica diante das dificuldades na escolarização de crianças de anos iniciais
}

\begin{abstract}
Resumo:
O presente artigo versa sobre uma pesquisa realizada em uma escola pública da rede federal brasileira, que se detinha a investigar de que forma ocorre a aprendizagem das crianças dos anos iniciais do ensino fundamental, as quais enfrentavam dificuldades escolares, mediante uma ação pedagógica específica. Foi utilizado como método a pesquisa qualitativa sob forma de pesquisa-ação e, como metodologia de análise, a análise textual discursiva. Para discussão dos dados, foram adotadas as principais referências da Psicopedagogia, e da ludicidade. Salienta-se que o achado de maior destaque na pesquisa refere-se à percepção de que a superação das dificuldades escolares das crianças participantes ocorreu à medida que iam modificando o lugar simbólico que ocupavam perante si, a tarefa e seus pares: do lugar da impossibilidade ou da não possibilidade, para o reconhecimento de sua capacidade. Nesse processo, fatores como as características de organização da ação, pautada pela perspectiva lúdica, e a sustentação emocional dada aos participantes foram fundamentais para a conclusão da tarefa, revelando grandes desafios que estão implicados na docência.
\end{abstract}

\section{Palavras-chave:}

Aprendizagem. Psicopedagogia. Ludicidade. Escolarização.

\section{School learning and pedagogical action in the face of difficulties in the schooling of children in the early years}

\footnotetext{
Abstract:

This article deals about a research realized in a public Brazilian federal school, that investigated how children of the First Years of Elementary School learn, who faced school difficulties, through a specific pedagogical action. The methodology was qualitative research in the form of Research-Action and, as methodology of analysis, Discursive Textual Analysis. In order to discuss the data, the main references were from Psychopedagogy and from ludic

1 Mestre em Educação, Doutoranda em Educação pela Pontifícia Universidade Católica do Rio Grande do Sul - PUCRS. E-mail: virginia.baum@acad.pucrs.br ORCID iD https://orcid.org/0000-0003-4770-8447

2 Doutora em Educação. Professora do Programa de Pós-Graduação em Educação da Pontifícia Universidade Católica do Rio Grande do Sul - PUCRS. E-mail: marlene.rozek@pucrs.br ORCID iD https://orcid.org/0000-0001-8740-6166
} 
characteristics. It should be emphasized that the finding of greater prominence in the research refers to the fact that the overcoming of school difficulties of the participating children occurred as they changed the symbolic place that they occupied before themselves, the task and their colleagues: from the place of the impossibility or non-possibility for recognition of their capacity. In this process, factors such as organizational characteristics of the action, guided by the ludic characteristics perspective, and emotional support given to the participants were of fundamental importance for the conclusion of the task, revealing great challenges that are implied in teaching.

\section{Keywords:}

Learning. Psychopedagogy. Ludic Characteristics. Schooling.

\section{Aprendizaje escolar y acción pedagógica ante las dificultades en la escolarización de niños de años iniciales}

\section{Resumen:}

El presente artículo versa sobre una investigación realizada en una escuela pública de la red federal brasileña, que se detuvo a investigar de qué forma ocurre el aprendizaje de los niños de los años Iniciales de la Enseñanza Fundamental, que enfrentaban dificultades escolares, mediante una acción pedagógica específica. Se utilizó como método la investigación cualitativa en forma de Investigación-Acción y, como metodología de análisis, el Análisis Textual Discursivo). Para la discusión de los datos se adoptaron las principales referencias de la Psicopedagogía y de la ludicidad. Se destaca que el hallazgo de mayor destaque en la investigación se refiere a percibir que la superación de las dificultades escolares de los niños participantes se dio a medida que éstos iban cambiando el lugar simbólico que lograban, la tarea y sus pares: del lugar de la imposibilidad o la no posibilidad, para el reconocimiento de su capacidad. En ese proceso, factores como las características de organización de la acción, pautada por la perspectiva lúdica, y el apoyo emocional dada a los participantes fueron de fundamental importancia para la conclusión de la tarea, revelando grandes retos que están implicados en la docencia.

Palabras clave:

Aprendizaje. Psicopedagogía. Ludicidad. Escolarización.

\section{Introdução}

Este artigo expõe os resultados de uma pesquisa sobre a temática do processo de aprendizagem no contexto escolar, de crianças que apresentavam dificuldades, especialmente no que diz respeito à produção textual em língua materna. Tem como propósito investigar como ocorrem os processos de aprendizagem e de escolarização das crianças dos anos iniciais do ensino fundamental, mediante sua participação em uma oficina, desenvolvida no contexto escolar. Além disso, fundamentado em uma visão psicopedagógica do processo escolar, buscou-se investigar a abrangência de ação desse formato de intervenção pedagógica em relação às defasagens no processo de escolarização, no suporte à aprendizagem escolar e na promoção de vínculos com a escola e com a aprendizagem, bem como analisar de que forma a ludicidade na escola pode proporcionar um espaço para o exercício da autoria de pensamento.

Esta investigação foi realizada em uma escola pública federal, no município de Porto Alegre (RS), cuja cultura pedagógica, recursos e currículo nos anos iniciais do ensino fundamental permi- 
tiram a exploração de práticas pedagógicas diferenciadas e inovadoras, tendo como foco principal a promoção das aprendizagens escolares, o engajamento e o desenvolvimento da autoria dos alunos. Sua clientela é bastante variada, visto que o ingresso dos alunos é realizado via sorteio público e há alta procura por vagas na instituição, atendendo, assim, a crianças de Porto Alegre e cidades vizinhas. Nessa escola, tendo como objetivo despertar a curiosidade das crianças e o prazer por aprender, foi implementada, em 2004, a prática pedagógica de oficinas no currículo dos anos iniciais. As oficinas são atividades semanais, com periodicidade semestral, que constam no currículo dos anos iniciais e cuja frequência é obrigatória. Nas oficinas, as crianças são agrupadas por interesse pela temática ofertada, compondo classes multisseriadas, nas quais a organização pedagógica é eminentemente lúdica; contudo, têm como pano de fundo objetivos de ensino específicos para a faixa etária atendida. Essas práticas apresentam excelente aceitação e engajamento por parte das crianças, fato confirmado pela avaliação institucional anual da referida escola, constituindo uma verdadeira marca no contexto escolar.

No entanto, observou-se que, mesmo nesse contexto tão rico em possibilidades, muitas crianças enfrentavam dificuldades na aquisição de conteúdos escolares, gerando defasagens. Para superar essa situação e prevenir o fracasso escolar, pensando nas especificidades da clientela extremamente diversificada, foi proposta a criação de um novo modelo de oficinas, nomeado como Oficinas de Aprendizagem. Essas oficinas, ao contrário do outro modelo, não constam na grade curricular, uma vez que não são obrigatórias, e se propõem a apoiar crianças com alguma dificuldade pontual em seu processo de escolarização de forma a prevenir a reprovação, o desenvolvimento do fracasso escolar e de dificuldades de aprendizagem. Para isso, as crianças são agrupadas conforme suas necessidades escolares e convidadas a participar de uma oficina extra, que também tem caráter lúdico, diferenciando-se do que normalmente é experienciado por elas em sala de aula. Essa prática teve início em 2013 e vem apresentando bons resultados na superação das dificuldades escolares. Assim, questionou-se por que algumas crianças não apresentavam bom desempenho escolar em sala de aula, mas nesse modelo de oficinas avançavam significativamente?

A partir dessa pergunta inicial, surgiu a presente pesquisa, a qual se dedicou a estudar o percurso de aprendizagem de dez alunos do $4^{\circ}$ ano do ensino fundamental que apresentavam defasagens na expressão escrita, especialmente na expressão completa de suas ideias e no encadeamento coerente do texto (introdução, desenvolvimento e conclusão). Além disso, foi possível identificar, por meio do histórico escolar das crianças, que elas passaram por situações familiares difíceis ao longo de sua vida escolar (p. ex., perda do pai/mãe, questões psicológicas, separação dos pais, abuso de drogas por familiar próximo, entre outros), o que também contribuiu para o desenvolvimento de fraturas importantes em sua escolarização. Todas compartilhavam sentimentos de impotência e incapacidade diante da escrita, constituindo verdadeiras crenças quanto às suas possibilidades de aprender tal conteúdo, impactando na forma como se relacionavam com a escolarização. Por tal razão, com frequência evitavam os desafios escolares, principalmente os que envolviam a escrita, apresentando reações como resistência, estagnação, distrações e fuga.

Assim, dados o contexto e os propósitos da pesquisa, utilizou-se como abordagem metodológica a pesquisa qualitativa sob a forma de pesquisa-ação (THIOLLENT, 2009), mediante a ação nomeada como Oficina de Aprendizagem Minimetragens, a qual foi desenvolvida especificamente para atender a esse público. Como referencial teórico para discussão dos dados, utilizou-se os principais autores da Psicopedagogia, tais como Paín (1996, 1999) e Fernández (1991, 2001a, 2001b); e da ludicidade, como Macedo, Petty e Passos (2005). A análise textual discursiva (MORAES; GALIAZZI, 2011) foi empregada como metodologia de análise. 


\section{O Método}

Como forma de garantir a coerência entre os objetivos da pesquisa e a realidade investigada, optou-se por desenvolver um estudo de cunho qualitativo. Segundo Minayo (2009), essa modalidade dedica-se a investigar os aspectos mais profundos das relações sociais, visando a compreender valores, percepções e atitudes, entre outros elementos, sempre os contextualizando de forma histórica, social e cultural.

Optou-se, também, por uma pesquisa na modalidade de pesquisa-ação, pois previa-se uma ação colaborativa no meio social investigado, com vistas à qualificação dos processos educativos, o que implica a participação ativa do pesquisador e da comunidade ao longo do decurso. Segundo Thiollent (2009, p. 16), trata-se de um modelo de pesquisa concebido e realizado "em estreita associação com uma ação ou com a resolução de um problema coletivo e no qual os pesquisadores e os participantes representativos da situação ou do problema estão envolvidos de modo cooperativo ou participativo", produzindo, assim, conhecimento e transformação social de uso efetivo e, no caso específico, mobilizando o sistema escolar na busca de soluções para seus problemas cotidianos, dado seu caráter conscientizador e comunicativo, deixando, desse modo, um legado para a comunidade atendida. Cabe destacar que a pesquisa-ação tem dois tipos de objetivos: o de ordem prática, que envolve a solução do problema, aqui representado pela superação das dificuldades relacionadas à produção textual dos participantes; e o que envolve a produção de conhecimento, relacionado ao objetivo da pesquisa em si.

Assim, em conjunto com a equipe dos anos iniciais da escola, elegeram-se as estratégias pedagógicas a serem adotadas junto aos alunos e os instrumentos de registro e socialização das práticas, a fim de coletar dados para a produção de conhecimento e de desenvolver uma proposta pedagógica efetiva para a ação. Como instrumentos de coleta de dados utilizaram-se a análise de documentos escolares e a observação participante registrada em diário de campo.

A análise de documentos escolares teve por objetivo colaborar na construção de uma contextualização dos sujeitos da pesquisa, na compreensão das demandas desses indivíduos, na elaboração do planejamento da ação e no acompanhamento dos desdobramentos da ação quanto à superação das dificuldades inicialmente apresentadas pelos alunos. Foram analisados: o plano de ensino do $4^{\circ}$ ano do ensino fundamental, para levantar demandas da escola; a produção textual das crianças envolvidas realizada na escola (antes, durante e após a ação), para acompanhar o desenvolvimento da escrita; e o histórico das crianças fornecido pela escola, para conhecer o sujeito ao qual a ação se voltaria, buscando atendê-lo da melhor forma possível e apoiá-lo de forma efetiva durante o processo.

Já a observação participante, registrada no diário de campo, teve por finalidade acompanhar o processo de ação e seus desdobramentos de ordem prática e de produção do conhecimento. Salienta-se que a discussão da pesquisa se baseou nesse diário de campo, pois nele foram feitos relatos de situações vivenciadas durante a oficina e de conversas informais com as crianças e demais membros da comunidade escolar. Ainda, cabe destacar que a elaboração do diário de campo se transformou em um processo reflexivo para todos os envolvidos, colaborando com o desenvolvimento da autoria e autoformação dos sujeitos, visto que se tratava de um momento de retomada e (re)elaboração de impressões, valores, compreensões, etc., contribuindo, assim, para a qualificação do planejamento da ação. Contudo, é importante realçar que antes da escrita no diário de campo se fazia uma reunião de discussão de impressões sobre a oficina, na qual, além das ministrantes, participavam também as professoras de referência das turmas. 


\section{A Ação}

Fundamentado nesta perspectiva, elaborou-se a ação Oficina de Aprendizagem Minimetragens, a qual pode ser definida como uma estratégia pedagógica, criativa e lúdica de apoio à compreensão, significação e construção da escrita, voltada para crianças com defasagens significativas na produção textual. Cabe esclarecer que as minimetragens são vídeos de curta duração (de 30 segundos até 5 minutos), que têm um enredo completo (introdução, desenvolvimento e conclusão), ou seja, uma narrativa apresentada sob o formato audiovisual. Essa ideia foi gestada tendo como princípio a necessidade de ressignificar a produção textual para essas crianças, permitindo que elas atribuíssem a esse objeto de aprendizagem outro significado, que não temor, incapacidade ou medo, além de levá-las a conhecer uma nova função para a escrita em suas vidas.

Partindo dessa perspectiva, surgiu o seguinte questionamento: como dar vida ao texto e implicar a criança no processo? Levando em consideração a forte atração das crianças por vídeos postados na internet, associada à demanda escolar, os alunos foram convidados a participar de uma oficina, cujo propósito era criar uma minimetragem para ser apresentada a seus colegas em uma mostra. Esse foi o objetivo prático da ação. Além disso, foram elencados objetivos pedagógicos implícitos na ação: elaborar e qualificar a produção de textos narrativos a partir da construção de roteiros; elaborar cenários; desenvolver a comunicação escrita, oral e visual; planejar e desenvolver estratégias de trabalho coletivo; e reposicionar a criança perante o grupo de pares e perante a tarefa escolar (especialmente a produção textual). A proposta pedagógica da oficina baseava-se no trabalho de elementos de desenvolvimento da consciência-textual ${ }^{3}$, presentes no plano de ensino do $4^{\circ}$ ano, mas sob um viés eminentemente lúdico e atrativo aos seus interesses. Ainda, a ação previa um cuidado psicopedagógico sobre as aprendizagens a serem construídas, tendo em vista o histórico das crianças e sua relação conturbada com o objeto de aprendizagem texto, prevendo-se de antemão as suas possíveis reações e o surgimento de questões simbólicas relacionadas às suas trajetórias de vida.

A ação ocorreu ao longo do primeiro semestre de 2015, iniciando-se no mês de abril, após uma criteriosa avaliação do perfil das crianças a serem convidadas. Salienta-se que, inicialmente, foram previstos dez encontros, mas houve paralisações nas atividades da escola e somente sete encontros foram realizados. Cabe destacar que os encontros eram semanais, com duração de aproximadamente 50 minutos, realizados no turno de aula das crianças, em horário previamente combinado com as professoras e as famílias.

A oficina foi ministrada pela pesquisadora, também orientadora educacional do grupo, e pela fonoaudióloga da escola, sendo acompanhadas por quatro estagiárias da fonoaudiologia, que tinham como objetivo do estágio trabalhar com questões preventivas relacionadas à expressão oral, produção escrita e leitura. Ao longo do semestre, a pesquisadora teve contato diário com as crianças envolvidas, bem como com a comunidade escolar.

Com base nessa configuração, o trabalho da ação foi dividido em quatro etapas: a primeira etapa foi chamada de pré-produção, a qual engloba o convite às crianças, a coleta do assentimento delas e o envio do Termo de Consentimento Livre e Esclarecido aos seus responsáveis (atividades não contabilizadas no número de encontros), bem como a análise de uma minimetragem e a construção de um cronograma (um encontro), a elaboração do roteiro (três encontros) e a construção do cenário (um encontro). A segunda etapa, chamada de produção, foi composta pelo planejamento da filmagem, pelo ensaio e pela filmagem propriamente dita (um encontro). $\mathrm{O}$

3 Conforme Pereira (2010), a consciência textual propõe-se a estudar e analisar as relações entre os elementos linguísticos que compõem um texto, bem como sua relação com o contexto, focando-se em elementos relacionados à estrutura, à coesão e à coerência, tais como: adequação do gênero textual, características de estrutura, desenvolvimento da temática, coesão lexical, correção gramatical e organização geral do texto. 
terceiro momento, chamado de pós-produção, foi constituído pelo processo de edição. A quarta etapa, chamada de première, compreendeu a mostra dos vídeos às demais crianças das turmas de $4^{\circ}$ ano (um encontro). Todas as etapas foram protagonizadas ativamente pelas crianças, as quais receberam apoio e orientação das ministrantes. A única etapa realizada pelas ministrantes foi o processo de edição, em razão do tempo escasso (encerramento do semestre letivo). Salienta-se que os objetivos propostos para a ação foram cumpridos e notou-se, durante e após o processo, que houve significativa evolução na qualificação da produção textual das crianças envolvidas em outros espaços escolares, bem como maior disponibilidade de enfrentamento dos desafios que surgem no processo de escolarização.

Quanto aos pressupostos que embasaram a ação, adotou-se o princípio da ludicidade como forma de organização do trabalho pedagógico e o cuidado psicopedagógico no planejamento e intervenção junto às crianças.

A dimensão lúdica aqui é entendida, conforme Macedo, Petty e Passos (2005, p. 16), como a forma natural de a criança ser e se expressar no mundo, sendo que para ela "apenas o lúdico faz sentido". Assim, uma proposta pedagógica que visa a significar conteúdos escolares na perspectiva da criança deveria, segundo os autores, levar em conta o caráter lúdico. Contudo, para os autores, a dimensão lúdica não pode ser confundida com o uso de jogos e brincadeiras, há atividades lúdicas que geram tensão e até mesmo desconforto nos participantes, mas mantêm o espírito lúdico. Macedo, Petty e Passos (2005) declaram que, para ser interessante para a criança, nessa perspectiva, uma tarefa deve ser simples, clara, direta, realizável, desafiadora e constante, tanto na forma quanto no conteúdo. Além disso, deve ter os seguintes indicadores: I) despertar o prazer funcional; II) ser desafiadora; III) ser possível; IV) possuir dimensão simbólica; e V) permitir a expressão construtiva e relacional. O primeiro indicador refere-se ao fato de a atividade despertar o prazer no momento da execução, trata-se da "alegria, que muitas vezes também é sofrimento, de exercitar um certo domínio, de testar uma certa habilidade, de transpor um obstáculo ou de vencer um desafio" (MACEDO; PETTY; PASSOS, 2005, p. 17), ou seja, o elemento motivador e engajador do processo, criando um sentimento de pertencimento à atividade. $\mathrm{O}$ segundo indicador refere-se ao interesse que a atividade desperta, e depende da forma como ela é proposta, do contexto ao qual se refere, das pessoas envolvidas e do sentido que cada sujeito atribui à tarefa. O indicador da possibilidade baseia-se no fato de que não se realizam tarefas impossíveis, tem por princípio mobilizar o desejo de seguir na tarefa e cumprir o desafio. Já a dimensão simbólica refere-se à relação estabelecida entre a criança e a atividade, conferindo-lhe um sentido particular, incluindo, de modo recíproco, o sujeito e a tarefa, abrindo espaço para a (re)criação de si e do mundo. Por fim, o quinto indicador refere-se à consideração dos diferentes pontos de vista, aberto às diferentes formas de expressão do sujeito, acolhendo-o em sua singularidade e apoiando-o na relação com o outro e com o mundo.

Outro pressuposto básico para o desenvolvimento da ação refere-se a considerar o processo de aprendizagem em uma perspectiva complexa e relacional, na qual está implicado o sujeito contextualizado. Aprender é considerado um processo de apropriação e posicionamento no mundo, que se inicia desde o nascimento. Para Paín (1996), a pessoa, desde seu nascimento, passa por um processo de apropriação da cultura humana por meio da aprendizagem, constituindo-se e (re) criando-se enquanto ser humano, agindo sobre o mundo ao longo de sua experiência de vida. A autora ainda acrescenta que é a partir dos primeiros vínculos estabelecidos com o outro e com o conhecimento que se molda uma matriz de aprendizagem individual, a qual se projetará sobre outros contextos de aprendizagem. Assim, a Psicopedagogia compreende a aprendizagem para além da escolarização, como um processo em contínua expansão, que se encerra apenas com a morte do indivíduo, e no qual estão inscritos fatores relacionados à constituição do sujeito, mas também outros, tais como a cultura, o contexto histórico e social, além da historicidade da pessoa e os vínculos desenvolvidos com os outros significativos e o mundo. Por isso, uma ação que contemple tal perspectiva deve levar em conta essa complexidade. 
Entre os fatores envolvidos na aprendizagem, intrínsecos aos sujeitos, Fernández (1991) cita as dimensões da aprendizagem: orgânica, corporal, intelectual e simbólica (ou desejante). A dimensão orgânica diz respeito ao organismo biológico da pessoa. A dimensão corporal, por sua vez, é constituída simbolicamente por meio das vivências do sujeito, é com o corpo que ele se apropria do organismo e faz seu uso conforme suas necessidades; por meio dele aprende, goza/sofre, (re) age, simboliza e registra experiências e desejos, atribuindo significado ao que o cerca. As dimensões intelectual (lógica) e simbólica (emocional/subjetiva) referem-se à estrutura do pensamento, o qual não diferencia processos cognitivos de emocionais, pois, segundo a autora, eles ocorrem simultaneamente, constituindo estruturas complementares inseparáveis.

Assim, a perspectiva aqui apresentada propõe-se a trabalhar com o sujeito real, tal como ele funciona, considerando suas particularidades constitutivas, potencialidades e necessidades. Nessa perspectiva, educar, uma das tarefas da escola, tal como afirma Paín (1985), adquire uma perspectiva ampliada: trata-se de inscrever o sujeito no mundo da cultura, fazendo, para isso, o uso de vínculos com objetos de aprendizagem que devem ser (res)significados ao longo de sua trajetória, permitindo-lhe constituir a si e ao mundo em que vive de maneira recíproca.

\section{Resultados da pesquisa: a produção do conhecimento}

Tendo em vista a base metodológica e epistemológica da pesquisa, optou-se pela análise textual discursiva - ATD (MORAES; GALIAZZI, 2011), desenvolvida especificamente para a análise de pesquisas qualitativas e que se propõe a trabalhar com a construção de categorias emergentes, como metodologia de análise de dados do diário de campo. Tal perspectiva permite fazer uma imersão profunda nas minúcias do texto, uma vez que propõe o exercício contínuo de reconstrução do material escrito, de forma a levar à impregnação do pesquisador no material analisado, revelando o interlocutor e dando-lhe voz. Ao todo, foram encontradas 823 unidades de sentido, constituídas a partir do corpus de análise, as quais foram organizadas em 14 categorias emergentes iniciais, que, por sua vez, foram reestruturadas em três categorias emergentes finais, que se propõem a explorar os objetivos da pesquisa e representam a visão de cada um dos grupos envolvidos no processo da ação. A primeira, denominada "Construções das crianças", aborda as representações das crianças participantes da oficina e se trata da categoria mais densa e que expõe o foco da pesquisa. Na segunda categoria, chamada de "O papel das ministrantes", são expostas as representações das ministrantes da ação, destacando-se a forma como a docência é conduzida de modo a efetivamente apoiar as aprendizagens das crianças. Já a última categoria, nomeada "Olhares externos à oficina", busca abordar como a oficina foi percebida pelos demais (professores, demais alunos e familiares).

\section{Construções das crianças}

Esta categoria representa o cerne da pesquisa, uma vez que busca apurar, a partir das ações e representações expressas pelas crianças, como elas transitaram na oficina e como ocorreram suas construções, reflexões e aprendizagens.

$\mathrm{O}$ achado de maior destaque nesta categoria refere-se a perceber que a superação das dificuldades escolares das crianças ocorreu à medida que iam modificando o lugar simbólico que ocupavam perante si, a tarefa e seus pares: do lugar da impossibilidade ou da não possibilidade, para o reconhecimento de sua capacidade. Para Fernández (1991), todos os ambientes pelos quais as pessoas transitam estão marcados pela via simbólica, que, por sua vez, é formada a partir das experiências de vida do sujeito. Ainda, é pela via do simbólico que o sujeito pode se colocar em 
relação, (re)organizando a vida afetiva e das significações. Assim, nesta pesquisa entende-se o lugar simbólico como a maneira particular como as pessoas se colocam em uma determinada posição relacional em um ambiente específico, o qual está marcado pela constituição subjetiva do sujeito.

Pode-se dizer que essa recolocação aconteceu porque a organização da ação previu trabalhar e acolher elementos da constituição simbólica da criança, especialmente pela via lúdica, abrindo um espaço transicional ${ }^{4}$ em que a autoria pôde ser exercida. Conforme Fernández (2001b), a ludicidade tem a propriedade de abrir espaço transicional, criando uma relação segura entre quem ensina, quem aprende e a aprendizagem, permitindo que o sujeito mova-se de maneira confiante por novos caminhos, até então não explorados, contribuindo, assim, para a construção de novos vínculos, significados e processos simbólicos, além de oportunizar o exercício da autoria de pensamento, ou seja, reconhecer-se como autor da sua própria história e das suas produções, responsabilizando-se pelo que é capaz de fazer, gerando implicação e desejo por aprender e movimentando os processos de aprendizagem como um todo.

Foi possível identificar, com base nos dados pregressos dos sujeitos da pesquisa, no contato direto com eles e nos relatos das professoras, que as crianças se sentiam impotentes diante dos desafios escolares. Quanto à escrita, elas tinham crenças que não condiziam com as suas reais potencialidades. Essas crenças eram expressas de forma muito sutil, no discurso ou no comportamento, e, facilmente, eram confundidas com outras questões, como indisciplina ou apatia: diziam não ter ideias (e evitavam o trabalho), acreditavam que estavam sempre erradas (e se calavam), diziam não gostar de escrever (quando, na verdade, isso era algo muito difícil para elas), ou, até mesmo, causavam alguma situação que boicotavam a tarefa, gerando conflitos. Esses sentimentos influenciavam de forma profunda a maneira como as crianças se relacionavam com os objetos de aprendizagem escolar, levando-as a crer que eram incapazes de escrever. Segundo Fernández (2001a), essa emocionalidade pode se sedimentar de forma a produzir um sintoma na aprendizagem, por isso a necessidade de ação preventiva em relação à produção de uma dificuldade de aprendizagem.

Por essa razão, uma das contribuições da pesquisa é expor a necessidade de se criar espaços, também no ambiente escolar, para que situações como essas possam ser ressignificadas a partir de um deslocamento do lugar simbólico que o sujeito ocupa perante os objetos de aprendizagem e os vínculos estabelecidos. Além disso, esse processo demanda daquele que exerce a função de ensinar um olhar sensível e atento.

Na presente ação, o deslocamento do lugar simbólico ocorreu desde o primeiro convite às crianças até o encerramento da oficina, com a mostra. O convite foi feito enfatizando o desafio, como uma oportunidade de fazer algo diferente, que lhes demandaria esforço e envolvimento, e não enfatizando as habilidades que lhes faltava. Tendo como base os interesses da faixa etária e a cultura do local, a organização do formato da ação despertou não apenas o interesse, mas também o engajamento, culminando no estabelecimento de vínculos saudáveis com a tarefa, os quais superavam o medo e a sensação de impotência.

Esses aspectos puderam ser percebidos pela crescente autonomia das crianças e em situações como, por exemplo, quando não queriam parar de trabalhar após o encerramento do período da oficina, ou quando elas iniciaram a oficina mesmo diante de um atraso das ministrantes, situações até então inéditas com esses sujeitos. Tais situações apontam para um (res)significar da tarefa escolar, uma vez que agir de modo autônomo só é possível quando a criança assume que pode realizar algo sozinha, sem ser autorizada, ou seja, que aprendeu e se reconhece potente diante do desafio.

Outra situação ocorreu durante a mostra: ao perceberem que tinham algo interessante a exibir aos seus colegas, e que foi muito bem aceito por eles, criou-se nos sujeitos da pesquisa uma

40 espaço transicional, segundo Winnicott (1975, p. 30), é uma "área intermediária de experiência, incontestada quanto a pertencer à realidade interna ou externa", a qual é experienciada ao longo da vida nas experiências mais intensas, estando intimamente relacionada com a atividade lúdica nas crianças, implicando, assim, na forma como se estabelece o vínculo com a realidade. 
sensação de reconhecimento pelo destaque positivo que receberam da turma. Esse momento contribuiu para que as crianças entendessem que tinham com o que contribuir com o grupo, tornando-se cada vez mais ativas nos espaços coletivos da escola, reduzindo-se, assim, os momentos de apatia e estabelecendo-se um vínculo (res)significado com o processo de aprender e mostrar o que sabe no ambiente escolar.

Percebeu-se que a oficina, implicada com a modificação do lugar simbólico que os sujeitos ocupavam no contexto escolar, repercutiu para além da qualificação da escrita das crianças envolvidas, pois elas avançaram nos relacionamentos e no posicionamento em sala de aula, tornando-se mais autônomas, confiantes e envolvidas com o processo de escolarização. Por tais razões, pode-se dizer que a oficina representou para seus participantes um lugar de descoberta da potência de cada um na escola, um lugar em que o desafio sustenta o interesse, e a possibilidade real de concretização da tarefa provoca a entrega à proposta, abrindo espaço para a função positiva da ignorância (PAÍN, 1999), ou seja, o que falta ao sujeito e que lhe provoca o desejo de conquistar, de aprender, de seguir adiante, revelando uma mudança no tipo de vinculação que a criança estabelece com os objetos de aprendizagem, no caso, na escola.

Outro fato interessante a ser destacado é que algumas crianças participantes da oficina, além de se tornarem mais ativas, começaram a se sentir capazes de apoiar os colegas e ajudá-los dentro de suas possibilidades. Como exemplo, cita-se o discurso de Máximo ${ }^{5}$ registrado no diário de campo (1/7/2015), referindo que já havia entendido como desenvolver o projeto da minimetragem: "ele disse que já sabia como funcionava e que poderia ajudar", que "gostaria de dar uma ideia: que poderíamos fazer essa oficina novamente, e os alunos que tivessem participado poderiam ser ajudantes dos novos que entrassem". Quanto ao deslocamento da criança da posição de aprendente para posição de ensinante ${ }^{6}$, Fernández (1991, p. 52) refere que se trata de um processo em que realmente ocorreu a "apropriação (aprendizagem), processando-a através de suas estruturas e seu saber pessoal", convertendo a "enseña em conhecimento". A autora afirma que tal processo ocorre quando da articulação das quatro dimensões da aprendizagem, destacando que o conhecimento provém do ensino, sistemático ou não, "mas a possibilidade de processar este conteúdo depende da presença, no sujeito, de uma estrutura cognitiva [...] e de um vínculo que possibilite representar esse conhecimento" (FERNÁNDEZ, 1991, p. 72), e esta vinculação ocorre a partir das oportunidades ofertadas ao sujeito para que possa se (re)constituir simbolicamente. Ainda, a autora destaca que a alternância entre as posições de ensinante e aprendente possibilita uma boa aprendizagem, uma vez que, ao conectar-se com a posição de ensinante, o sujeito reconhece que “já conhece e autoriza-se a mostrar, a fazer visível aquilo que conhece" (FERNÁNDEZ, 2001b, p. 59), conectando-se, assim, com sua autoria. Esse (re)conhecimento das próprias potencialidades também tem por virtude (re)colocar a criança em um lugar de possibilidade, abrindo espaço para a ação do sujeito de forma mais confiante, criando um ambiente de aprendizagem saudável que, conforme Fernández (2001b, p. 59), ocorre quando a situação de aprendizagem consegue "apelar ao sujeito ensinante dos aprendentes".

\section{O papel das ministrantes}

Esta categoria expõe como o papel do ensinante foi realizado na oficina e o lugar que ocupou em relação aos processos de aprendizagem e (re)elaboração das crianças participantes.

5 Os nomes dos participantes da pesquisa são fictícios.

6 Termos utilizados pela primeira vez por Alícia Fernández (1991) para designar o sujeito que aprende e o sujeito que ensina, respectivamente. 
Um elemento importante no desenvolvimento da oficina foi a forma como ocorreu a relação dos sujeitos da pesquisa com o outro, ministrante ou colega. Salienta-se que o desenvolvimento da oficina muitas vezes foi penoso, especialmente durante a construção do roteiro, e as dificuldades foram superadas a partir da sustentação emocional que o outro fornecia à criança diante de situações de angústia e frustração que o trabalho com o texto suscitava. Cabia às ministrantes apoiar as crianças na produção escrita de forma a problematizar as ideias relacionadas à produção textual e sua qualificação, mas também sustentá-las emocionalmente e dar limites para que o projeto da minimetragem efetivamente se concretizasse.

É interessante notar que, em determinado momento, as crianças apoiavam-se mutuamente, inclusive dando suporte emocional para seu parceiro de trabalho, como no trecho do diário de campo (referente ao dia 26/6/2015) em que consta: "Cheguei e Máximo estava estirado na cadeira [...]. Flor chega e convoca Máximo ao trabalho. Nesse momento, Máximo reage de forma diferente, se reorganizando na cadeira". Essa situação demonstra a constituição de outra aprendizagem, de caráter reacional.

Nesse processo de relação com o outro, ainda se destaca como contribuição pedagógica da oficina o fato de uma espécie de contrato de trabalho ter sido feito com os participantes, bem como a construção de um cronograma, a fim de comprometê-los com o processo. O contrato de trabalho estabelecido seguiu a definição de Visca (2010, p. 61), ou seja, um acordo verbal no qual "explicitam-se e fixam-se as condições de acordo com as quais se trabalhará". Assim, as crianças, desde o início, tinham clareza do que a oficina demandaria delas e o que implicava o desenvolvimento da proposta. Foi muito útil às ministrantes para retomar o trabalho sempre que necessário, como quando surgiam reações de fuga da tarefa (expressa pelo envolvimento com situações paralelas, como brincar, distrair-se ou conversar sobre assuntos alheios à proposta). As ministrantes recorriam ao contrato de trabalho e ao cronograma para voltar a implicar os sujeitos no processo, representando não só o estabelecimento de limites, mas também o desenvolvimento de consciência quanto às consequências que tais atitudes teriam para efetivação da proposta.

Ainda, algumas crianças se utilizaram desses recursos para, de maneira autônoma, organizarem-se no tempo e nas tarefas. Bárbara, por exemplo, antes de iniciar as tarefas, consultava o que estava previsto para aquele dia e iniciava seu trabalho de onde havia parado.

A intervenção do ministrante, por sua vez, sempre demandou sensibilidade e firmeza. Tinha como princípio o fato de que "a aprendizagem vai guardar [...] os resquícios daquilo que lhe serviu de base" (BARONE, 2013, p. 62), denunciando o mundo simbólico do sujeito, e causando repercussões no presente. Nessa perspectiva, o outro se torna um ponto de transferência das experiências do passado para situações do presente e o sujeito, por sua vez, demanda, inconscientemente, sustentação para (re)elaborar a experiência atual e superar o que sente diante do desafio provocado pelo objeto de aprendizagem. Esse processo, conforme Barone (2013), contribui para a (res)significação das estruturas simbólicas e vínculos estabelecidos com as aprendizagens que o sujeito construiu até então em sua experiência de vida, auxiliando também no deslocamento do lugar simbólico, abrindo espaço para que a aprendizagem ocorra. No entanto, tal processo demanda muito daquele que exerce a função de sustentação, uma vez que a experiência a ser ressignificada causa sofrimento ao sujeito e, por isso, ele reage à intervenção.

Assim, pode-se dizer que um dos valores da oficina é a constituição de um espaço transferencial e relacional, no qual a criança pode reviver, de forma protegida, situações a serem (res) significadas. Acredita-se que a constituição desse espaço seguro pode abrir brechas no mundo simbólico da criança de forma a influenciar, mesmo que vagarosamente, sua experiência de escolarização e movimentar as dimensões da aprendizagem, permitindo a constituição de novas aprendizagens (res)significativas, sendo o papel do ministrante essencial no processo, demonstrando a complexidade da tarefa docente. 


\section{Olhares externos à oficina}

Esta categoria detém-se na abrangência da oficina em outros espaços que não no núcleo em que a ação efetivamente ocorreu, apresentando como professoras, familiares e demais membros da comunidade perceberam a ação.

O processo de organização da oficina foi realizado em parceria com as professoras, que sempre apoiaram o desenvolvimento da ação. Também, como forma de mantê-las envolvidas no processo, optou-se por dar-lhes retorno sobre como havia sido cada um dos encontros. Da mesma forma, elas sempre mantinham as ministrantes informadas sobre qualquer repercussão da oficina em sala de aula. Ou seja, desenvolveu-se um trabalho colaborativo que se retroalimentava, tanto em estratégias quanto em informações. Cita-se aqui um trecho do diário de campo, quando perguntado para uma das professoras sobre repercussões da ação na sala de aula: "as crianças da oficina estavam ficando mais abertas à escrita, percebendo sua responsabilidade quanto às produções [...]", seguindo com explicações sobre mudanças atitudinais e avanços pedagógicos das crianças.

Alguns familiares, mesmo indiretamente, relataram perceber mudanças na relação de seus filhos com a escola. Por exemplo, cita-se um trecho do diário de campo em que o pai de Sávio relata que seu filho "mostrou em casa o certificado [que ganhou na mostra] e que estava muito orgulhoso da conquista" e que eles ficaram felizes e o incentivaram a continuar se esforçando para obter novas conquistas.

Quanto aos demais membros da comunidade escolar, cita-se um trecho do diário de campo no qual a coordenadora pedagógica da escola, que estava presente na mostra, elogiou e parabenizou a produção das crianças, demonstrando surpresa quando a pesquisadora lhe contou que todas tinham dificuldades escolares de diferentes ordens.

Através desses diferentes olhares, pode-se perceber a confluência de perspectivas que também influenciam as aprendizagens das crianças e, parafraseando a fala de uma das professoras (diário de campo), é possível afirmar que a aprendizagem ocorre a partir de um "somatório de fatores", em um fluxo temporal, no qual cada um que está implicado no processo sente a repercussão da ação do outro. Assim, a partir dessa experiência é possível afirmar que a ação pedagógica extrapola os muros da escola, pois estão implicados não só o sujeito que aprende, mas todo o contexto no qual ele está inserido, de forma a afetarem-se mutuamente. Daí outra contribuição da oficina: ter clareza de que não basta trabalhar com a criança, há de se pensar em como envolver cada esfera que faz parte de seu contexto social, de forma a apoiá-la, da melhor maneira possível, em seus processos de aprendizagem e escolarização. Ou, como expresso por Fernández (1991), atuar sistemicamente nos vínculos e significações do aprender, sustentando o desejo da criança, facilitando, assim, a mobilização do conhecimento e da informação, com vistas à constituição de novas aprendizagens nos ambientes frequentados pela criança.

\section{Considerações finais}

A escrita é um ato de entrega e coloca em evidência a subjetividade do sujeito, seus pensamentos, a forma como percebe o mundo e, por isso, trata-se de uma tarefa complexa, especialmente para aqueles que se encontram fragilizados pelos estigmas da impossibilidade ou da não possibilidade. Assim, como consequência, suas reações diante de uma folha em branco: sucumbem à angústia, negam-se, buscam envolver-se com outra situação, boicotar a tarefa ou ter atitudes confrontativas diante daquilo que percebem como ameaça. Embora tal situação possa ser comum nas escolas brasileiras, poucas vezes se busca compreender o motivo de um semblante fechado, de um gesto agressivo, e ali pode haver um sujeito que se utiliza desses artifícios para esconder suas marcas, suas dores. Essas são as crianças que participaram desse processo de pesquisa, as quais deman- 
davam outro olhar e sustentação para avançarem na escolarização, assim como outras tantas que estão nos bancos escolares.

Percebeu-se que o processo de aprendizagem escolar das crianças envolvidas na pesquisa ocorreu por meio da modificação do lugar simbólico que ocupavam perante si, a tarefa e seus pares: do lugar da impossibilidade ou da não possibilidade para o reconhecimento de sua potencialidade o que se refletiu na relação com o grupo de pares e com o objeto de aprendizagem, impactando suas vidas como um todo. Para isso, fez-se necessário apoiá-las na sustentação do desejo de concluir a tarefa, mantendo o vínculo com a proposta. Demandaram suporte de outra pessoa, a qual exercia a função de ensinante no momento (seja a ministrante, seja o colega), e do espírito da ludicidade. Tal tarefa demonstrou ser bastante desafiadora para todos os envolvidos, pois não se tem preparação técnica durante a formação docente, por isso, encontra-se baseada na sensibilidade daquele que assume o desafio de ensinar e deseja, em seu íntimo, que as crianças aprendam.

Outro fator que contribuiu para a desmistificação das crenças tanto das crianças quanto da possibilidade de aprendizagem foi a constituição de espaços de exercício da autoria, o que gerou segurança para que as crianças pudessem se expor de forma confiante e segura. Nesse processo, as intervenções foram significativas para que as crianças se sentissem efetivamente protagonistas no processo e sustentadas em suas necessidades, abrindo espaço para o desejo e o autorreconhecimento de suas potencialidades.

Quanto ao legado da oficina para a atuação pedagógica, percebeu-se que o ensino claro e objetivo de conteúdos pedagógicos e de estratégias de revisão, essenciais à realização de uma escrita narrativa qualificada, foram fatores marcantes para que as crianças compreendessem o que a escola estava lhes exigindo, facilitando a execução da tarefa e a aquisição de aprendizagens escolares, constituindo um verdadeiro contrato pedagógico e implicando na segurança das crianças com relação à conclusão da tarefa, criando pertencimento ao espaço escolar. Nesse processo, o uso de objetos concretos também foi facilitador da construção narrativa, uma vez que era compatível com o desenvolvimento cognitivo das crianças envolvidas, demonstrando, dessa forma, a necessidade de o professor conhecer os fatores envolvidos na aprendizagem e no exercício da docência para qualificá-la.

Contudo, o principal valor pedagógico que a Oficina de Aprendizagem Minimetragens deixou para o processo de escolarização de crianças com dificuldades de aprendizagem foi a explicitação da complexidade da tarefa docente. Tal função requer a constituição de um olhar atento e disponível às crianças, não as pré-julgando por suas atitudes, mas buscando compreendê-las e sustentá-las no processo, de modo a superar o medo e a sensação de incapacidade que, na condição de alunas, carregam em tão tenra idade.

\section{Referências}

BARONE, Leda Maria Codeço. Algumas contribuições da psicanálise para avaliação psicopedagógica. In: OLIVEIRA, Vera Barros de; BOSSA, Nádia A. Avaliação Psicopedagógica da criança de zero a seis anos. 21. ed. Petrópolis: Vozes, 2013. p. 57-86.

FERNÁNDEZ, Alicia. A Inteligência Aprisionada: abordagem Psicopedagógica clínica da criança e sua família. Porto Alegre: Artmed, 1991. 261p.

FERNÁNDEZ, Alicia. Os Idiomas do Aprendente: Análise das modalidades ensinantes com famílias, escolas e meios de comunicação. Porto Alegre: Artmed, 2001a. 223p.

FERNÁNDEZ, Alicia. O Saber em Jogo: A Psicopedagogia propiciando autorias de pensamento. Porto Alegre: Artmed, 2001b. 179p. 
MACEDO, Lino; PETTY, Ana Lúcia Sícoli; PASSOS, Norimar Christe. Os jogos e o Lúdico na Aprendizagem Escolar. Porto Alegre: Artmed, 2005. 110p.

MINAYO, Maria Cecília de Souza (org.). Pesquisa Social: teoria, método e criatividade. 28 ed. Petrópolis: Editora Vozes, 2009. 108p.

MORAES, Roque; GALIAZZI, Maria do Carmo. Análise Textual Discursiva. 2. ed. Ijuí: Ed. Uniijuí, 2011. 223p.

PAÍN, Sara. Diagnóstico e Tratamento dos Problemas de Aprendizagem. 3.ed. Porto Alegre: Artes Médicas, 1985. 86p.

PAÍN, Sara. Subjetividade e Objetividade: relações entre o desejo e conhecimento. São Paulo: Centro de Estudos Educacionais Vera Cruz, 1996. 123p.

PAÍN, Sara. A Função da Ignorância. Porto Alegre: Editora Artes Médicas Sul Ltda, 1999. 199p.

PEREIRA, Vera Wannmacher. Aprendizado da Leitura e Consciência Linguística. In: ENCONTRO CELSUL, 9., 2010, Palhoça. Anais eletrônicos [...]. Palhoça: Universidade do Sul de Santa Catarina, 2010. Disponível em: http://www. celsul.org.br/Encontros/09/artigos/Vera\%20Pereira.pdf. Acesso em: 06 set. 2015.

THIOLlENT, Michel. Metodologia da Pesquisa-Ação. 17. ed. São Paulo: Cortez, 2009. 132p.

VISCA, Jorge. Clínica Psicopedagógica: Epistemologia Convergente. São José dos Campos: Pulso Editorial, 2010. 160p.

WINNICOTT, Donald Woods. O brincar e a realidade. Rio de Janeiro: Imago Editora Ltda, 1975. 208p.

Data de submissão: 31/01/2021

Data de aceite: 08/04/2021 